\title{
Hastiges Essen erhöht Risiko für ein Metabolisches Syndrom
}

\section{Wer seine Mahlzeiten hastig ver- schlingt, erhöht sein Risiko für ein Metabolisches Syndrom deutlich. Darauf verweisen japanische Autoren von der Universität Hiroshima.}

Die Autoren hatten 1.083 Personen rekrutiert, die im Jahr 2008 kein metabolisches Syndrom aufwiesen. Anhand ihrer Essens-Geschwindigkeit wurden sie in drei Kategorien eingeteilt: langsam, normal oder schnell. 84 Personen hatten nach fünf Jahren ein Metabolisches Syn- drom entwickelt, definiert als Vorliegen von wenigstens drei der Faktoren abdominelle Adipositas, hoher Nüchtern-BZ, Bluthochdruck, hohe Triglyzeride oder niedriges HDL-Cholesterin.

Die Risiken, ein Metabolisches Syndrom zu entwickeln, betrugen 2,3\% für Personen, die gemütlich aßen, 6,5\% für normale Esser und 11,6\% für die Eiligen, die ihre Mahlzeiten hastig verschlangen. Letztere zeigten insbesondere häufiger eine Zunahme von Taillenumfang und Gewicht sowie hohe Blutzuckerwerte.

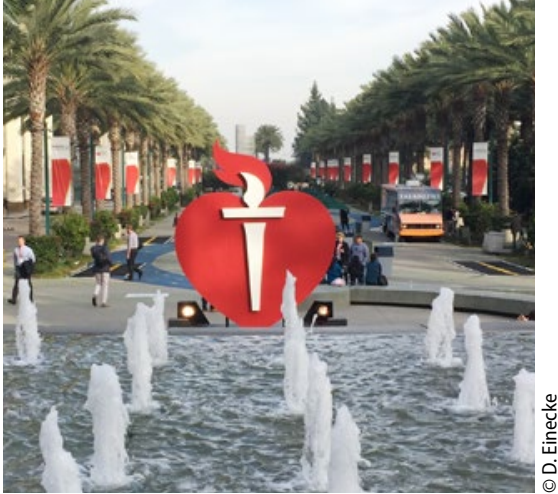

„Wer schnell isst, neigt dazu, kein Sättigungsgefühl zu entwickeln und zu viel zu essen. Zudem verursacht hastiges Essen größere Glukoseschwankungen, die zu einer Insulinresistenz führen können, erklärte Studienautor Dr. Takayuki Yamaji. Sein Fazit: Langsames Essen sollte Teil der Lifestyle-Interventionen zur Prävention des Metabolischen Syndroms werden.

- DE

- American Heart Association, Scientific Sessions 2017

\section{Junge Diabetiker}

\section{Herztodrisiko ist achtfach erhöht}

Junge Diabetiker weisen, allen Fortschritten beim Management der Stoffwechselerkrankung zum Trotz, eine erheblich höhere Mortalität als NichtDiabetiker auf: Das Risiko, aufgrund einer Herzkrankheit zu sterben, liegt um den Faktor 8 höher, die Gesamtmortalität um den Faktor 5.

_ Mit diesen Zahlen sorgten dänische Forscher um Jesper Svane von der Universitätsklinik in Kopenhagen auf dem AHA-Kongress in Anaheim für Aufsehen. Die dringliche Konsequenz lautet, dass junge Diabetes-Patienten eng bezüglich kardiovaskulärer Erkrankungen überwacht werden müssen.

Die Studiengruppe bestand aus der gesamten dänischen Bevölkerung. Überwacht wurden alle Personen, die in den Jahren 2000 bis 2009 zwischen 1 und 35 und zwischen 2007 und 2009 dann 36 bis 49 Jahre alt waren. Im Beobachtungszeitraum von 10 Jahren waren 14.294 Personen dieser Kohorte gestorben.

Mit Hilfe des dänischen Arzneimittelregisters konnte ermittelt werden, wer an Diabetes litt. Unter den Verstorbenen waren 669 Diabetiker (5\%), 471 mit Typ 1 und 198 mit Typ 2. 34\% der jungen Diabetiker starben an kardialen Ursachen, ein für diese Altersgruppe erstaunlich hoher Prozentsatz. 118 von ihnen erlitten einen Ein-Sekunden-Herztod.
Die kardiale Mortalität bei Diabetes betrug 68,3 pro 100.000 Patientenjahre verglichen mit 8,2/100.000 bei Nicht-Diabetikern. Die Mortalität am plötzlichen Herztod belief sich auf 34,8 (Diabetes) vs. 4,7 (Nicht-Diabetes) pro 100.000. DE

- American Heart Association, Scientific Sessions 2017

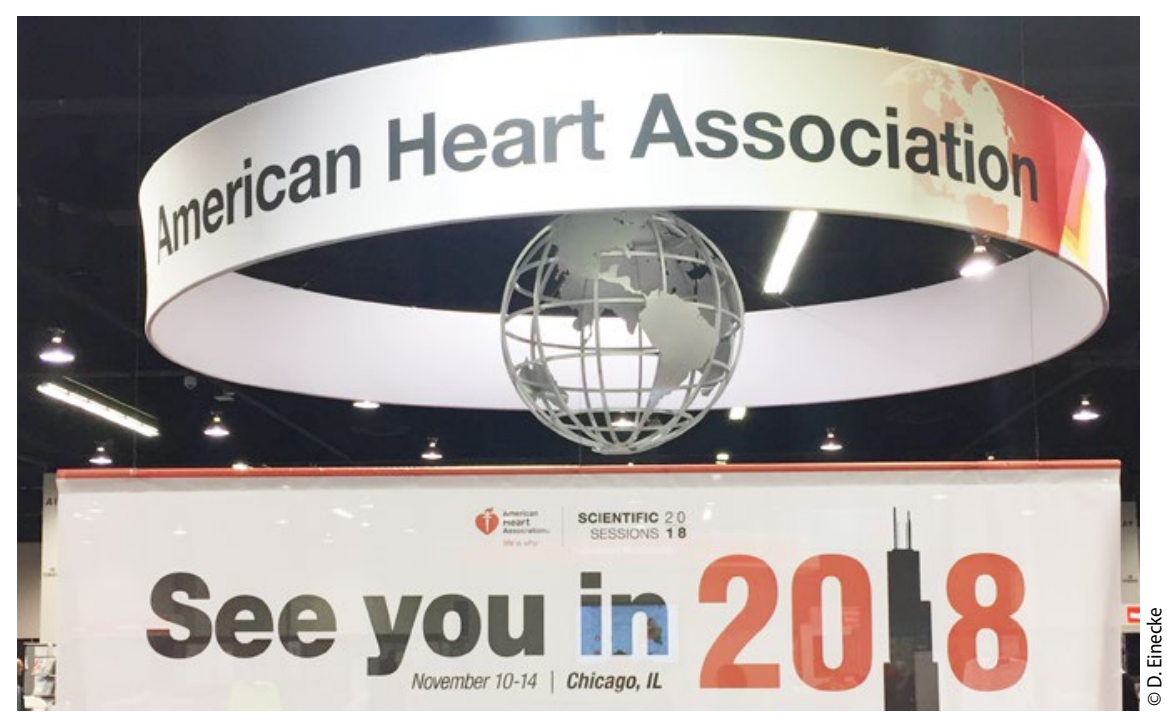

